\title{
Inquiry-Based Learning in Information Science
}

\section{Antje Michel and Hans-Christoph Hobohm}

Inquiry-based learning has selectively found its way into the teaching of information science - not as a didactic guiding principle, however. In the following article, the basic conditions for research in information science and the application of methods in the discipline will be used to work out the opportunities provided by using inquiry-based learning formats in information science. ${ }^{1}$

\subsection{Basic Conditions for Information Science Research}

Information science is a relatively new discipline within the scientific landscape. The increasing production of scientific information as well as its integration into mechanisms of economic exploitation and political utilization - which, for example, became apparent in 1957 as a result of what became known as the "Sputnik crisis" - required that the process of conveying information be professionalized to the same degree as the process of generating information in research and development (Kuhlen 2013). A major impetus for

\footnotetext{
${ }^{1}$ This article focuses on the didactic potential of inquiry-based learning in German information science. Determining the extent to which the presented inventory is also of international relevance would require closer consideration.
}

A. Michel, Prof. Dr. ( $₫)$

Fachhochschule Potsdam, Fachbereich Informationswissenschaften,

Professur für Informationsdidaktik und Wissenstransfer, Postdam, Germany

e-mail:michel@fh-potsdam.de

H.-C. Hobohm, Prof. Dr.

Fachhochschule Potsdam, Fachbereich Informationswissenschaften,

Professur für Bibliothekswissenschaft, Potsdam, Germany

e-mail: hobohm@fh-potsdam.de

H. A. Mieg (ed.), Inquiry-Based Learning - Undergraduate Research,

https://doi.org/10.1007/978-3-030-14223-0_14 
the development of academic information science in the Western world came in the wake of the social and scientific-political discourse as a result of the Weinberg report, as "information," understood as the meritorious good and common good, drew increasing attention (Weinberg et al. 1963).

In Germany, information science was developed as a concept based on the documentation science founded in approximately 1895 by Paul Odlet. In terms of content, these days they are an integration of documentation science, library science and archival science and focus on the social concepts of "information" and "knowledge" from the perspectives of information processing, of the representation of knowledge, of "information retrieval" (thus the computer-aided search for complex content), of information behavior and of information transfer (Umlauf 2011). In the international context, they have always been associated with the provision of information as "library and information science" (abbreviated as LIS).

Although information science is more or less extensively anchored at a total of 12 institutions of higher learning in Germany and information science research activities occur at a pace commensurate with this number, Germany lacks a genuine information science research culture. There are three essential reasons for this:

First, a large proportion of scientists in information science and research in Germany also belong to other disciplines. This is the result of the fact that a high proportion of information science education takes place at universities of applied sciences. Since these institutions do not possess an independent right to award doctorates, German information science has a small number of highly talented junior researchers. In the AngloAmerican and Scandinavian countries, information science is established in postgraduate studies (Bawden and Robinson 2012).

Secondly, despite the attention in terms of scientific policy paid to the central concepts of information science, there is no institutionalized funding structure for research in information science in Germany. This is reflected especially prominently in Germany in the absence of a continuous funding line in the German Research Foundation (DFG). The lack of a funding structure makes it difficult to develop a longer-term epistemological and research-related discourse for the further development of the discipline of information science.

Thirdly, the training of junior scientists is primarily practice-oriented. This is due, on the one hand, to the highly profession-related design of the curricula in the corresponding bachelor's degree programs at the universities of applied sciences, which is highly focused on the professions, and on the study interests of students on the other, which are highly focused on professional training, and finally on the prevalence of practice orientation in existing research. The result of the high practical relevance of education results is that it is only occasionally possible for students to develop a scientific identity that is characterized by information science. The perception that a familiarity with scientific methods and working methods is an essential qualification for a later occupational or academic career is simply less pronounced (Booth and Brice 2004). 


\subsection{Research Methodology in Information Science and Opportunities Through the Use of Inquiry-Based Learning}

According to Hider and Pymm (2008), research in information science is characterized by:

1. an overall broad quantitative and qualitative range of methods,

2. a focus on the application of quantitative research methods,

3. the dominance of surveys and experiments as methods,

4. a high proportion of publications without reference to a research method.

Bawden and Robinson (2012) expound on the problems related to the sample sizes, which are frequently small, and the result thereof, which is that information science research is insufficiently generalizable. An analysis of big data, which would be expected due to the technical roots of information science in documentation science and the consequent obvious methodical approaches such as logfile analyses, could not yet be entirely demonstrated in the study by Hider and Pymm with their dataset from 2005. Insofar as it is possible to take the more recent findings from Greifeneder (2014) - which focused on information behavior research and concluded that the use of big data analyses has thus far been low, but is ever increasing - and transfer those findings to the entire discipline, such analyses seem to be slowly finding their way into information science.

A transfer of the data collected by Hider and Pymm to the situation facing German information science should be treated with caution, however. To begin with, the data of Hider and Pymm focuses on Anglosphere publications and, as already mentioned above, the establishment of information science academia is significantly more advanced in the United States and in Great Britain than it is in Germany. In addition, the authors have focused explicitly on basic research and the analysis of practice-oriented research and its methods. However, as already described, this makes up the majority of German-language research in information science. A cautious thesis as to the methodological situation in German information science could be that, due to the basic conditions that are implemented, it can be assumed that the application of methods will be based more on smallscaled quantitative and on more or less theory-saturated qualitative studies than was determined for the Anglosphere research area.

That methodological reflection in German information science tends to still be in its infancy can also be deduced from the fact that the first German-language manual for information science methodologies was only published in 2013. Even in this manual, information science is referred to as an empirical discipline characterized by a low proportion of epistemological meta-reflection and a range of methods largely derived from the social sciences, ethnology and information science (Umlauf et al. 2013). Historically rooted between technology and social science, information science offers a diverse range of methods that, in Germany, is extended into research and teaching in information science due to the integration of scientists originating in other disciplines. The challenge for 
research in information science is in competently applying this range of methods in research and teaching. It is desirable for information science to have a shared body of methods and the classification thereof as canon for teaching, as Hider and Pymm also explain in their article.

In addition to the wide range of methods that characterizes research in information science, the discipline has an additional special characteristic, which is relevant in terms of its use in inquiry-based teaching-learning methods: In practice, the central field of activity for "information professionals" lies in the collection, development and provision of information for a specific target group and in determining competencies for dealing with existing information resources and their carrier media. In terms of methodology, information professionals must not only to be able to organize their own information needs, but must also be able to take on roles in order to anticipate and serve the information needs of other target groups. This requires a capacity for reflection, understood as meta-competence, which involves reflecting one's own position in relation to the situation of another person and the parameters of the relevant social environment (Hobohm et al. 2015). Therefore, practitioners must be especially capable of researching the need for information as well as the specific handling of information for their target groups, and of developing creative concepts in order to adequately satisfy them. Even in professional practice, researchoriented behavior is effective and should therefore be the subject of teaching in information science.

The following goals for the use of concepts and methods of inquiry-based learning in information science can be derived from the previous explanations: To begin with, students should be familiarized with the process of scientific work in a discipline with a very heterogeneous range of methods, and should be given the ability to work with the methods in a research-oriented manner. Moreover, students should be socialized so that they develop research-oriented thinking and activity, giving them the ability to objectively apply the instruments of information science research appropriately, both within the context of a later academic career and, in particular, when starting a career in an information science profession.

\subsection{Concept and Implementation of Inquiry-Based Learning in Information Science}

To date (i.e., at the time of writing the original German version of this article in February 2016), inquiry-based learning has only occasionally been implemented in individual courses of the various information science degree programs in Germany, if at all. It is only seldom applied as a guiding didactic concept for an academic education in information science. Comparing the curricula for information science bachelor's degree programs in the German-speaking area shows that project work is implemented as an element of inquiry-based learning at almost all institutions of higher learning; however, the percentage of such work in the workload of the overall curriculums is frequently low or cannot be 
precisely determined. The research orientation of teaching and the use of research-based teaching-learning methods as a didactic guiding principle in teaching are only explicitly emphasized in the study documentation at HTW Chur and FH Potsdam.

To date, there have been very few meta-reflective publications regarding a research orientation in information science. One such publication describes the situation at HTW Chur (Schuldt and Mumenthaler 2015). Although there are differences between German and Swiss academic information science, the situation is quite comparable in terms of its strong focus and location at a university of applied sciences. As part of a curriculum revision in the fall of 2015, HTW Chur has begun to expand the already-selective incorporation of scientific methodology in its information science curriculum. In the new curriculum at HTW Chur, in addition to courses for imparting survey knowledge into the research methods in the field, there are now a greater number of project courses, in which elements of the scientific research process or an entire student research method are planned, carried out and documented independently (ibid.). Additional publications have come into existence within the context of a research project at the University of Applied Sciences Potsdam (see Box 14.1).

Among the various concepts and models for inquiry-based learning which are in part described in this book, the Zurich framework (Tremp and Hildbrand 2012) is especially suited in our view for providing a framework for the requirements on information science in terms of a concept for inquiry-based learning as worked out in this article (for more, see Mieg, in this volume).

The starting point for the Zurich framework is the belief that the main objective of academic studies is a "university education" (ibid., p. 104). Providing students with the ability "to think and act in a scholarly manner" (ibid.) can be derived as a general study objective from the postulate of a university education. The framework makes the aforementioned problems in developing a scholarly identity in information science clear: "A university education thereby focuses on the development of an academic personality, which is characterized in equal degree by creativity and methodological skill, and which is committed to scholarly attitudes and values" (ibid., p. 104-105, translated).

In our view, one of the strengths of the Zurich framework is that, at the course level, there are no requirements for the compulsory use of certain teaching formats, which may not really be transferrable to the specific basic conditions of a university and its curricula under certain circumstances. Rather, it encourages retaining the diversity of forms of teaching and developing the strengths of each for integration into the framework at the level of curriculum development. The visualization of the frameworks can be found in this volume in the article by Mieg (Fig. 1.3).

Using the Zurich framework, a curriculum need not necessarily be completely redesigned and based entirely on extensive student research projects. Rather, it is much more important to provide students early with a general overview of the research process as reflected in the specific subject culture. It is possible to explain, practice and reflect on the different stages of the research process that build on one another in a modular way within the various courses. If the principle of "research as a central idea" is maintained 


\section{Box 14.1: Developing Research Competencies in the Information Professions}

In 2012-2014, a BMBF research project at the University of Applied Sciences Potsdam investigated the interdisciplinary competencies in the professional practice of information specialists: "Akademische Kompetenzen in den Informationsberufen (AKIB)" ("Academic competencies in the information professions"). One of the results was the empirical identification of the core competencies of this professional field as a metacognitive reflective competence. On the one hand, this is expressed in the taking on of roles in conjunction with the intermediary position of information professionals; on the other, however, it also points to the important core task of information scientists in the generation of data via data ("metadata" such as catalogs or other "finding aids"). Against this background, an e-learning-based "self-study course on scientific work" was developed for students and continuing education participants in the Department of Informational Sciences, with the aim of familiarizing them with the concept of university study as research right from the first semester on. Unlike other introductions to scholarly work, the model - which has been designed to be appealing with interactive multimedia - focuses less on formalities and more on research attitude. It is available to students throughout their studies, beyond the workshop module in the first semester, in the mode of peer learning.

Accompanying this, an online training course was developed for lecturers teaching blended learning courses concerning implementing the format of inquiry-based learning, which likewise addresses the metacognitive approaches of the professional field and which is based on connectivist didactic approaches. Understanding the metacognitive situation of "learning how to learn" is especially important for instructors in this context (cf. AKIB n.d.; Hobohm et al. 2015; Pfeffing et al. 2018).

Another important component of the commitment of the University of Applied Sciences Potsdam on the topic of analyzing and conveying competency in information science within the meaning described here is the establishment of the internationally innovative field of "informational didactics" with a newly established professorship.

throughout the entire curriculum, then students should be socialized to such a degree that they are prepared to carry out their research project as a "final project."

The activities associated with implementing inquiry-based learning as a didactic guiding principle in the Department of Informational Sciences at FH Potsdam will be described in greater detail below. The process can be described in a manner analogous to the Zurich framework in terms of fundamental didactic ideas and the institutional levels.

FH Potsdam provides good basic conditions for developing inquiry-based learning formats and integrating these in the degree programs at the university: In addition to a largescale third-party project for inquiry-based learning " $F L^{2}$ " (inquiry-based 
learning - instructional research), a development program for interdisciplinary courses focused on inquiry-based learning has existed for years (cf. depiction of the Interflex program in the article by Prytula et al., in this volume). The aim of these tools is to link research activities within the university with teaching. The Department of Informational Sciences' requirements for systematically anchoring inquiry-based learning in the curricula of the degree programs are favorable:

1. The Department of Informational Sciences is research-oriented and has strong thirdparty funding.

2. It follows the link between research and teaching in the further development of the curricula for all degree programs. Thus didactic elements of inquiry-based learning, for example, are implemented in all three reaccredited bachelor's degree programs, which will start as of the 2016/17 winter semester.

3. Instructional student research projects have been successfully carried out for years.

Concrete planning for the bachelor's degree programs explicitly integrate inquirybased learning. The implementation strategy was developed in the same way as the Zurich framework to the effect that inquiry-based learning is not focused on individual, largescale project phases, but as a didactic principle throughout the entire curriculum.

In the new curricula of the three bachelor's degree programs that are occurring in a partially integrated manner, a teaching format was introduced right in the first semester with the workshop module ( 2 semester hours per week), which made the research process in information science tangible right at the start of the course of studies through independent student research projects. This workshop module enables the didactically accompanied implementation of the first student research projects. Thus the research-based project work is to be practiced in a didactic form and transferred to practical knowledge.

What is especially important about the concept is that all instructors in the degree programs are involved in teaching in the workshop module. For example, it should hereby make the methodological breadth of information science tangible to students. Moreover, the didactic fine-tuning among teachers requires a consistent understanding of the different methodological and epistemological approaches to their discipline. During the course of study, the "workshop" is included repeatedly as a didactic form, e.g. in relatively comprehensive "project and supplementary seminars" (in part as interdisciplinary InterFlex courses) or, insofar as is useful to the content or didactic intent, in partial aspects of other courses.

According to the Zurich framework, the use of the other forms of teaching should be done in a reflective manner in that the instructors situate the teaching method in the research process in order to also consistently anchor the focus on the research process where the acquisition of specialist knowledge is in the foreground in terms of content, and to allow reflection on the transfers of accumulated knowledge to the research process. 


\subsection{Outlook: On the Perspective of Inquiry-Based Learning in Information Science}

The most important measure for promoting inquiry-based learning in information science is promoting the awareness that research-oriented behavior is an essential basic competence not only in information science, but also in practical occupations related to information science. An important tool here is in experimenting with the form of inquiry-based learning in information science, in the research accompanying these activities and in obtaining feedback regarding the relevance of the research-oriented behavior in the information professions postulated in this article, for example by means of ongoing follow-up studies of graduates from the degree programs for information science and establishing other forms of theory-practice transfer.

It is also necessary to strengthen and increase the visibility of information science research at the level of science politics, because inquiry-based learning requires lively research at the academic training institutions. To this end, German information science must first grow stronger as a discipline in quantitative, institutional but also discursivemethodological terms, as explained in detail above. The publication of basic textbooks and handouts in German must be intensified. The discipline's status as a "small subject area" must also be pursued more intensely in terms of science politics and be reflected in the funding lines of the science-promoting institutions. The relevance of information science research will play an important role in this. The research affinity of the discipline, which has already been fostered to some extent by the Bologna Process, must be further increased, for example through the continued development or redevelopment of master's (and bachelor's) degree programs in information science, as well as through increased funding by third parties and, in particular, through the shared acceptance of research as the core activity of the research and teaching of the subject, which are strongly anchored in practice.

In addition, the relevance of research-oriented behavior for the dynamic professional field of information professionals must be promoted at the level of the information professions. Within this context, information-science research facilities must also establish themselves as agents in the transfer from theory to practice, that is, as information facilities within the sense of practical action based on evidentially founded information.

A quantitative and qualitative intensification of both internal and external scientific communication is needed in order to realize this agenda. Since the previous activities, statements and position papers failed to demonstrate the desired success, new strategies and formats of knowledge transfer need to be developed. Complementary to this strategy, what we have stated thus far will result in a completely distinct research program for informational didactics and the transfer of knowledge, which consists of working out the specifics of various information assets against the background of the prerequisites and practices of the respective, relevant knowledge cultures, as well as of the development of 
suitable didactic formats for the transfer of information and knowledge (cf. also Ballod 2007). Information literacy is not equally universal, despite the apparent public perception to the contrary due to the ubiquitous availability of information and knowledge resources. Rather, the correct handling of information and knowledge requires the systematic and scientifically secure construction of specific information-related competencies based on the development of meta-reflective, research-oriented behavior.

\section{References}

Akademische Kompetenzen in den Informationsberufen (AKIB) (n.d.). Projektwebsite. Retrieved 11 April 2016 from http://AKIB.fh-potsdam.de

Ballod, M. (2007). Informationsökonomie - Informationsdidaktik: Strategien zur gesellschaftlichen, organisationalen und individuellen Informationsbewältigung und Wissensvermittlung. Bielefeld: Bertelsmann.

Bawden, D./Robinson, L. (2012). Introduction to Information Science (Foundations of the information sciences). London: Facet.

Booth, A./Brice, A. (Hrsg.). (2004). Evidence-based practice for information professionals: A handbook. London: Facet.

Greifeneder, E. (2014). Trends in information behaviour research. Information Research, 19(4), 159-170.

Hider, P./Pymm, B. (2008). Empirical research methods reported in high-profile LIS journal literature. Library \& Information Science Research, 30(2), 108-114.

Hobohm, H.-C./Pfeffing, J./Imhof, A./Groeneveld, I. (2015). »Reflexion« als Metakompetenz: Ein Konzeptbegriff zur Veranschaulichung akademischer Kompetenzen beim Übergang von beruflicher zu hochschulischer Qualifikation in den Informationsberufen. In W. K. Freitag/R. Buhr/ E.-M. Danzeglocke/S. Schröder/D. Völk (Hrsg.), Übergänge gestalten: Durchlässigkeit zwischen beruflicher und hochschulischer Bildung erhöhen (S. 173-191). Münster: Waxmann.

Kuhlen, R. (2013). Information - Informationswissenschaft. In R. Kuhlen/W. Semar/D. Strauch (Hrsg.), Grundlagen der praktischen Information und Dokumentation (6. Auflage) (S. 19-42). Berlin: De Gruyter Saur.

Pfeffing, J./Mauch, M./Hobohm, H.-C. (2018). Die Potenziale Forschenden Lernens heben eine Online-Weiterbildung zur Moderation von Lernprozessen für Hochschullehrende. In J. Lehmann/H. A. Mieg (Hrsg.), Forschendes Lernen. Ein Praxisbuch (S.472-485). Potsdam: FHP.

Schuldt, K./Mumenthaler, R. (2015). Forschungsmethoden in die Praxisausbildung einbinden? Ansätze an der HTW Chur. Libreas. Library Ideas, 11(27). Retrieved 15 Narch 2016 from http:// libreas.eu/ausgabe27/04schuldt/

Tremp, P./Hildbrand, T. (2012). Forschungsorientiertes Studium - universitäre Lehre: Das »Zürcher Framework« zur Verknüpfung von Lehre und Forschung. In P. Tremp/T. Brinker (Hrsg.), Blickpunkt Hochschuldidaktik: Vol. 122. Einführung in die Studiengangentwicklung (S. 101116). Bielefeld: Bertelsmann.

Umlauf, K. (2011). Bibliotheks- und Informationswissenschaft. In K. Umlauf/S. Gradmann (Hrsg.), Lexikon der Bibliotheks- und Informationswissenschaft (S. 91-93). Stuttgart: Hiersemann. 
Umlauf, K./Fühles-Ubach, S./Seadle, M. (Hrsg.). (2013). Handbuch Methoden der Bibliotheksund Informationswissenschaft: Bibliotheks-, Benutzerforschung, Informationsanalyse. Berlin: De Gruyter Saur. Retrieved 15 March 2016 from http://www.degruyter.com/doi/ book/10.1515/9783110255546

Weinberg, A. M./et al. (1963). Science, Government, and Information: The Responsibilities of the Technical Community and the Government in the Transfer of Information. Washington D.C. Retrieved 15 March 2016 from http://eric.ed.gov/?id=ED048894

Open Access This chapter is licensed under the terms of the Creative Commons AttributionNonCommercial-NoDerivatives 4.0 International License (http://creativecommons.org/licenses/bync-nd/4.0/), which permits any noncommercial use, sharing, distribution and reproduction in any medium or format, as long as you give appropriate credit to the original author(s) and the source, provide a link to the Creative Commons licence and indicate if you modified the licensed material. You do not have permission under this license to share adapted material derived from this chapter or parts of it.

The images or other third party material in this chapter are included in the chapter's Creative Commons licence, unless indicated otherwise in a credit line to the material. If material is not included in the chapter's Creative Commons licence and your intended use is not permitted by statutory regulation or exceeds the permitted use, you will need to obtain permission directly from the copyright holder.

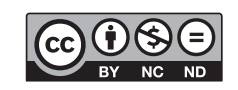

